\title{
Enhanced Turbine Monitoring Using Emissions Measurements and Data Reconciliation
}

\author{
Mohammed S. Syed, ${ }^{\dagger}$ Kerry M. Dooley, ${ }^{\dagger}$ Frantisek Madron, ${ }^{\ddagger}$ and F. Carl Knopf $*^{, \dagger}$ \\ ${ }^{\dagger}$ Department of Chemical Engineering, Louisiana State University, Baton Rouge, LA 70803 \\ ${ }^{\ddagger}$ ChemPlant Technology, 40001 Czech Republic \\ *Correspondence should be addressed to F. Carl Knopf (knopf@lsu.edu)
}

\begin{abstract}
$\underline{\text { Abstract }}$
Standard monitoring within a gas-turbine based cogeneration system includes key flow rates, temperatures, pressures and turbine vibration. These standard measurements can be enhanced with continuous emissions monitoring to help pinpoint system problems. A combination of these measurements, a fast $N O_{x}$ prediction model and data reconciliation constitute an improved monitoring and diagnostic tool that can quantitatively predict the existence of turbine problems (for example, damaged combustor nozzles) even when standard turbine monitoring indicates no problems exist.
\end{abstract}

\section{Introduction}

The cogeneration of heat and power is integral to many industrial processing sites. Cogeneration systems represent a large capital investment with costs approaching \$1MM/MW of installed capacity. The gas turbine is the heart of the cogeneration plant. For gas turbines, the early detection of many common problems is difficult, but of critical importance. Unexpected shutdowns of a gas turbine can result in a large increase in the electricity demand charge from the local utility. Such increases typically last one year.

Repair of the combustion chamber in a nominal $20 \mathrm{MW}$ turbine can easily exceed $\$ 1 / 4 \mathrm{MM}$. On a routine basis (per 4,000 hours of operation or every six months) turbines are physically inspected to ensure that their bearings and rotors are intact, e.g., no damaged blade tips. Also, turbine vibration is continuously monitored to detect these same problems. A large body of literature is devoted to the importance of performance monitoring and early problem detection. The components of monitoring and detection include data extraction, fault detection, fault location and prognosis [1-4]. Much of the current literature focuses on fault location algorithms which can be broken down into pattern recognition methods such as fuzzy logic [5, 6], genetic algorithms [7], Bayesian belief networks [8-10], and neural networks [11-14] and model identification methods such as Kalman filtering [15] and weighted least squares [16-18]. But despite continuous developments in all of these physical and computational techniques, serious gas turbine problems can still quickly develop before corrective actions can take place. For example, fuel nozzles can develop internal cracks that may not immediately affect the gross (vibrational or temperature/pressure) performance of the gas turbine. Such problems are not immediately detectable by standard performance monitoring/diagnostic tools. 
In this work we present an improved diagnostic tool to indicate the early onset of problems in a turbine system by utilizing measured $N O_{x}$ emissions. The quantity of emissions, including $N O_{x}$, $\mathrm{CO}, \mathrm{SO}_{2}$, VOC and particulates, is regulated at most facilities, so highly accurate $\mathrm{NO}_{x}$ measurements in the exhaust stack are available. As an added benefit, early detection of turbine problems by this method can also help prevent emissions violations. This work significantly contributes to fault simulation methodology by coupling the thermodynamically consistent GRIMech 3.0 for natural gas combustion to emissions measurements and engine performance. This deterministic method does generate an easy to implement strategy involving polynomials, because it is just an empirical fit of observed emissions. The current model (using GRI-Mech 3.0) accounts for 53 species and 325 reactions.

All useful diagnostic tools require highly reliable data. Gross error detection and data reconciliation are established techniques to ensure that plant data (chemical and petrochemical, mineral processing, etc.) satisfy material and energy balances [19, 20], leading to improved accuracy. These techniques are of increasing importance to the power industry including nuclear power plants [21], coal-fired [22] and combined cycle power plants [23]. Data reconciliation can be used to establish validated cogeneration system operating conditions using the measured flow rates for steam production, natural gas, air, and water injection, along with measured temperatures and pressures. An accurate temperature within the turbine's annular combustion chamber is usually not measured, due to the harsh environment [24], but this temperature is obtainable (observable) from the data reconciliation process. In this work we formulate a chemical reaction model for a natural gas feed in order to relate measured $N O_{x}$ emissions to the annular combustor temperature. Data reconciliation with the global test method is then used to identify problems within major components of the cogeneration system. At most installations, even if a change in $N O_{x}$ emissions were detected, this change would not become part of the data reconciliation or used to help pinpoint where problems may exist, because an annular combustor performance model would also be needed.

\section{Process Description}

\section{$\underline{2.1 \text { LSU's Cogeneration System }}$}

Louisiana State University installed a 20 MW cogeneration system in 2006 to help meet campus electricity and steam demands. The system utilizes a GE LM-2000 aeroderivative engine operating with natural gas fuel. Water injection is one of the technologies used to control the $N O_{x}$ emissions [25]. Figure 1 depicts the cogeneration system, consisting of an air compressor, annular combustor, gas turbine, power turbine and heat recovery steam generator (HRSG). Ambient air (state 0) passes through a cooler to adjust its temperature to a nominal $520 \mathrm{R}$. Regardless of the ambient temperature, state 1 will always be $\sim 520 \mathrm{R}$, because this helps maximize turbine performance. Water is the heat exchange fluid in the air cooler, chilled water used on hot days or chilled water produced otherwise. This consistent incoming air temperature

at state 1 does influence modeling and observed $N O_{x}$. Natural gas, with compressed air and injected water, is burned in the combustor, which delivers hot exhaust gases to the gas generating 
turbine (expander). We assume (for calculation purposes) that all the work done by the gas generating turbine powers the compressor. The power turbine is connected to an electrical generator. The HRSG includes both economizer and evaporator sections.

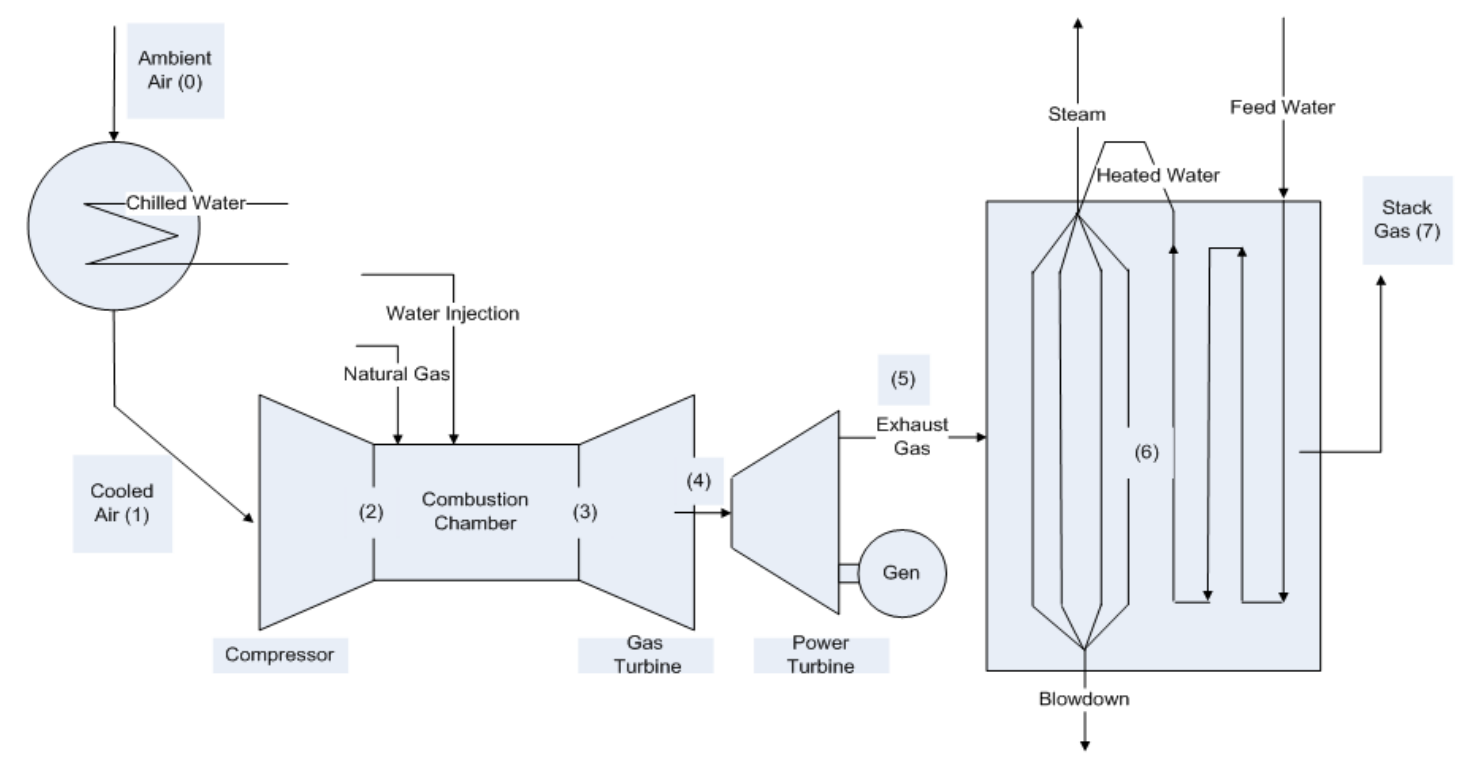

Figure 1: Gas turbine cogeneration system - air cooler, turbine system and HRSG

Water injection in the combustion chamber moderates the flame zone temperature, both reducing the $N O_{x}$ and increasing the power output. The water exits with exhaust gas in the stack. The drawbacks of water injection include additional costs for treated water, but, more seriously, water injection can promote abnormal wear of the fuel injectors or the turbine blades.

A Vivicom Continuous Emissions Monitoring System (CEMS) monitored the $N O_{x}$ emissions at the stack continuously. The CEMS pumps a sample from the stack, converts any $\mathrm{NO}_{2}$ to $\mathrm{NO}$, then measures the combined $N O_{x}$ in the range of 0-450 ppmvd (ABB Limas 11UV photometric analyzer). The meter is calibrated daily with a bottled calibration gas (Airgas, Certified Standard). To measure the $C O$ and any unburnt hydrocarbon emissions, the exhaust was sampled into evacuated $500 \mathrm{~mL} 316$ stainless steel bombs. These samples were analyzed using an Agilent 490 Micro GC containing 5A molecular sieve and Porapak U columns. Analysis conditions were $10 \mathrm{~min}, 80^{\circ} \mathrm{C}$, helium carrier gas. Fuel (natural gas) samples were also analyzed similarly, as $N O_{x}$ and other emissions vary with fuel composition.

\subsection{Standard Cogeneration System Diagnostic Tools}

The flow rates, temperatures, pressures and turbine vibration monitored by the distributed control system can help identify any abnormalities in the combustor/gas turbine. A key diagnostic is the exhaust gas temperature spread at the power turbine inlet. As shown in Figure 2, 11 thermocouples at this location are mounted radially. Current diagnostic strategy is to flag a temperature difference greater than $150 \mathrm{~F}$ between any two thermocouples. For any temperature difference exceeding $200 \mathrm{~F}$, usual practice is to shut down the turbine. 


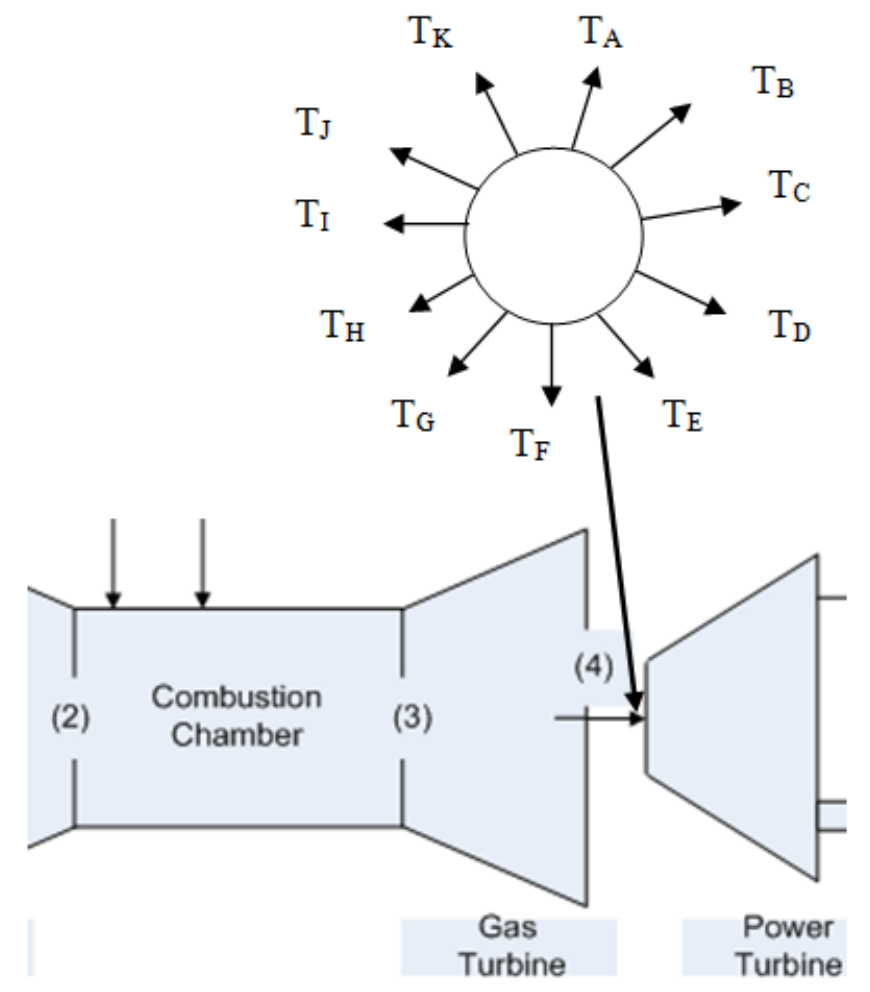

Figure 2: Temperature measurements at the power turbine inlet

Table 1 shows a typical set of data from the cogeneration system at LSU.

Table 1 Key measured values and variable definitions from LSU's cogeneration system

\begin{tabular}{|c|c|c|c|c|}
\hline Name & Description & Value & Units & $\frac{\text { Standard }}{\text { Deviation }}$ \\
\hline$F_{\text {Air }}$ & Air flow rate & 145 & $\mathrm{lb} / \mathrm{s}$ & 20 \\
\hline$T_{1}$ & Air T leaving Air Cooler & 519.94 & $\mathrm{R}$ & 5 \\
\hline$P_{2}$ & Air P leaving Compressor & 253.38 & psia & 1 \\
\hline$T_{2}$ & Air T leaving Compressor & 1260.48 & $\mathrm{R}$ & 10 \\
\hline$F_{N G}$ & Natural Gas flow & 3.0139 & $\mathrm{lb} / \mathrm{s}$ & 0.07 \\
\hline$F_{\text {Water,Inj }}$ & Water Flow injected Combustor & 3.145 & $\mathrm{lb} / \mathrm{s}$ & 0.1 \\
\hline$P_{3}$ & Products gas P leaving Combustion Chamber & 253.38 & psia & 1 \\
\hline$P_{4}$ & Products gas P leaving Gas Generating Turbine & 56.9 & psia & 1 \\
\hline$T_{4}$ & Products gas T leaving Gas Generating Turbine & 1836.34 & $\mathrm{R}$ & 30 \\
\hline$P_{5}$ & Products gas P leaving Power Turbine & 14.82 & psia & 1 \\
\hline$T_{5}$ & Products gas T leaving Power Turbine & 1386.67 & $\mathrm{R}$ & 60 \\
\hline$P_{6}$ & Products gas P leaving Evaporator & 14.82 & psia & 1 \\
\hline$T_{6}$ & Products gas T leaving Evaporator & 914.67 & $\mathrm{R}$ & 50 \\
\hline$P_{7}$ & Products gas P leaving Economizer & 14.82 & psia & 1 \\
\hline$T_{7}$ & Products gas T leaving Economizer & 787.67 & $\mathrm{R}$ & 20 \\
\hline$F_{\text {Prod }}$ & Combustion products flow rate & 147.6208 & $\mathrm{lb} / \mathrm{s}$ & 20 \\
\hline
\end{tabular}




\begin{tabular}{clcrr}
$\dot{W}_{\text {Net }}$ & Net Power produced by power turbine & 21.39 & $\mathrm{MW}$ & \\
$\dot{W}_{\text {Net }}$ & Net Power produced by power turbine & 20273.04 & $\mathrm{Btu} / \mathrm{s}$ & 0.01 \\
$\dot{Q}_{C C, \text { Loss }}$ & Heat loss in Combustion Chamber & 1125 & $\mathrm{Btu} / \mathrm{s}$ & 250 \\
$N O_{x}$ & $N O_{x}$ Ppm leaving in the stack & 38 & $\mathrm{ppmvd}$ & 1 \\
$F_{\text {Water,Econ }}$ & Feed Water flow entering Economizer & 24.4444 & $\mathrm{lb} / \mathrm{s}$ & 1.2222 \\
$P_{\text {Water,Econ }}$ & Feed Water P entering Economizer & 239 & $\mathrm{psia}$ & 1 \\
$T_{\text {Water,Econ }}$ & Feed Water T entering Economizer & 677.67 & $\mathrm{R}$ & 30 \\
$P_{\text {Water,Evap }}$ & Heated Water P entering Evaporator & 198 & $\mathrm{psia}$ & 1 \\
$T_{\text {Water,Evap }}$ & Heated Water T entering Evaporator & 780.67 & $\mathrm{R}$ & 30 \\
$F_{\text {Steam }}$ & Steam flow & 24.17 & $\mathrm{lb} / \mathrm{s}$ & 0.725 \\
$P_{\text {Steam }}$ & Steam P & 140.9 & $\mathrm{psia}$ & $\mathrm{NA}$ \\
$T_{\text {Steam }}$ & Steam T & 821.67 & $\mathrm{R}$ & 1 \\
$F_{\text {Water, BlowD }}$ & Blowdown flow - saturated water & 0.28 & $\mathrm{lb} / \mathrm{s}$ & 0.1 \\
\hline
\end{tabular}

In Table 1 the instrument standard deviations were determined either from manufacturerprovided data or from a large data sample when the system was at steady state [20].

\section{Model Development - Developing an Improved Diagnostic Tool for Turbine Systems}

To indicate the onset of problems in the turbine system and generally improve cogeneration system diagnostics, we will utilize existing $N O_{x}$ measurements. But, in order to do this we must have a model which relates measured $N O_{x}$ to the environment where it was created. This model must be both accurate and "fast" in order to be utilized within a "real-time" data reconciliation. There are three general modeling categories for coupling emission measurements to combustor performance: (1) empirical and semi-empirical models; (2) chemical reactor networks (CRN) utilizing GRI-Mech 3.0 [26] (or an equivalent detailed chemical kinetics mechanism); (3) models based on computational fluid dynamics (CFD). Generally computational time increases with each method in the order listed. CFD modeling of combustors requires thousands of control volumes currently necessitating the use of reduced kinetics mechanisms [27]. For this work we will utilize CRN modeling.

\subsection{Data Reconciliation}

The data reconciliation problem is,

$$
\begin{gathered}
\text { Minimize } f=\sum_{\substack{i, \text { measured } \\
\text { variables }}}\left(\frac{x_{i}^{+}-x_{i}}{\sigma_{i}}\right)^{2} \\
\text { Subject to: } g_{k}\left(x_{i}, y_{j}\right)=0 \quad k=1, \ldots, K
\end{gathered}
$$


where $x_{i}^{+}$are the measured process variables, $x_{i}$ are the reconciled values, $\sigma_{i}$ are standard deviations of the measurement instrument, $g_{k}\left(x_{i}, y_{j}\right)$ are the material and energy balances, and $y_{j}$ are unmeasured process variables.

For the cogeneration system we can write energy balances for the air cooler, compressor, combustion chamber, gas generating turbine, power turbine, and HRSG evaporator and economizer. We can write material balances for the combustion chamber and HRSG. We equate the energy balances for the compressor and gas generating turbine giving six energy balances and two material balances. We performed the data reconciliation using the measured variables provided in Table 1; additional details for performing data reconciliation are provided elsewhere [28, 29]. Reconciled values for measured variables including $F_{N G}, F_{A i r}$, and $F_{\text {Water,Inj }}$ were determined. The exhaust gas temperature from the combustor, $T_{3}$, is typically not measured as instrument life is short due to the harsh (high temperature) environment [24]. The data reconciliation itself determined a "best value" for $T_{3}$, which can be classified as an unmeasured but observable variable. Here $T_{3}$ was determined from the energy balances around the combustion chamber and the compressor/gas generating turbine. This $T_{3}$ value itself does not constitute a better or new diagnostic tool; however, it proves useful in the reaction model. Also, in this data reconciliation formulation the measured $N O_{x}$ was not used nor its value reconciled, as it does not directly appear in the primary energy and material balances around any of the unit operations.

Now we consider using the measured $N O_{x}$ in the stack as part of a strategy to indicate the onset of problems in the combustor/turbine. As the distribution of air, water and fuel with respect to position changes in the flame zone of a combustor, a change in the $N O_{x}$ emissions from the stack will ultimately be observed. For our improved monitoring/diagnostic tool we couple the measured $N O_{x}$ emissions with the reconciled system variables (especially $F_{N G}, F_{A i r}, F_{W a t e r, I n j}$ and $T_{2}$ ) and the unmeasured temperatures of the combustor ( $T_{\text {Flame }}$ and also $T_{3}$ ) to diagnose combustor problems (e.g., the possibility of bad nozzles). This coupling, via a fast $N O_{x}$ reaction model, requires understanding the gas turbine annular combustor details. Ultimately the fast $N O_{x}$ reaction model will be used in the constraints (equation (2)), allowing $N O_{x}$ emissions measurements to appear in the objective function (equation (1)). The key to the model is to establish a kinetically rigorous and thermodynamically consistent basis coupling $N O_{x}$ emissions to the combustor performance. As detailed below, we used GRI-Mech 3.0 (which accounts for 325 reactions and 53 species) with 22 perfectly stirred reactors (PSR) to account for the combustor flame zone (here $F_{N G}, F_{A i r}, F_{W a t e r, I n j}, T_{F u e l}$, and $T_{2}$ are used) followed by a PSR and plug flow reactor in series to model the remainder of the combustor allowing determination of $T_{3}$ and $\mathrm{NO}_{x}$. This model when used in conjunction with the material and energy balance constraints reflects both $\mathrm{NO}_{x}$ emissions and other variables (both measured and observed).

\section{The Gas Turbine Annular Combustor}

An annular gas turbine such as the GE LM-2000 mixes and combusts air, water, and fuel at high temperature and near constant pressure. Thirty fuel nozzles introduce both the water and natural gas fuel to the compressed air. The combustor is depicted in Figure 3. Compressed air mixes 
and combusts with the fuel and water at the nozzles. In addition some compressed air flows inside and outside the annular combustor to help cool the combustor as well as help cool the shaft connecting the gas turbine to the compressor.

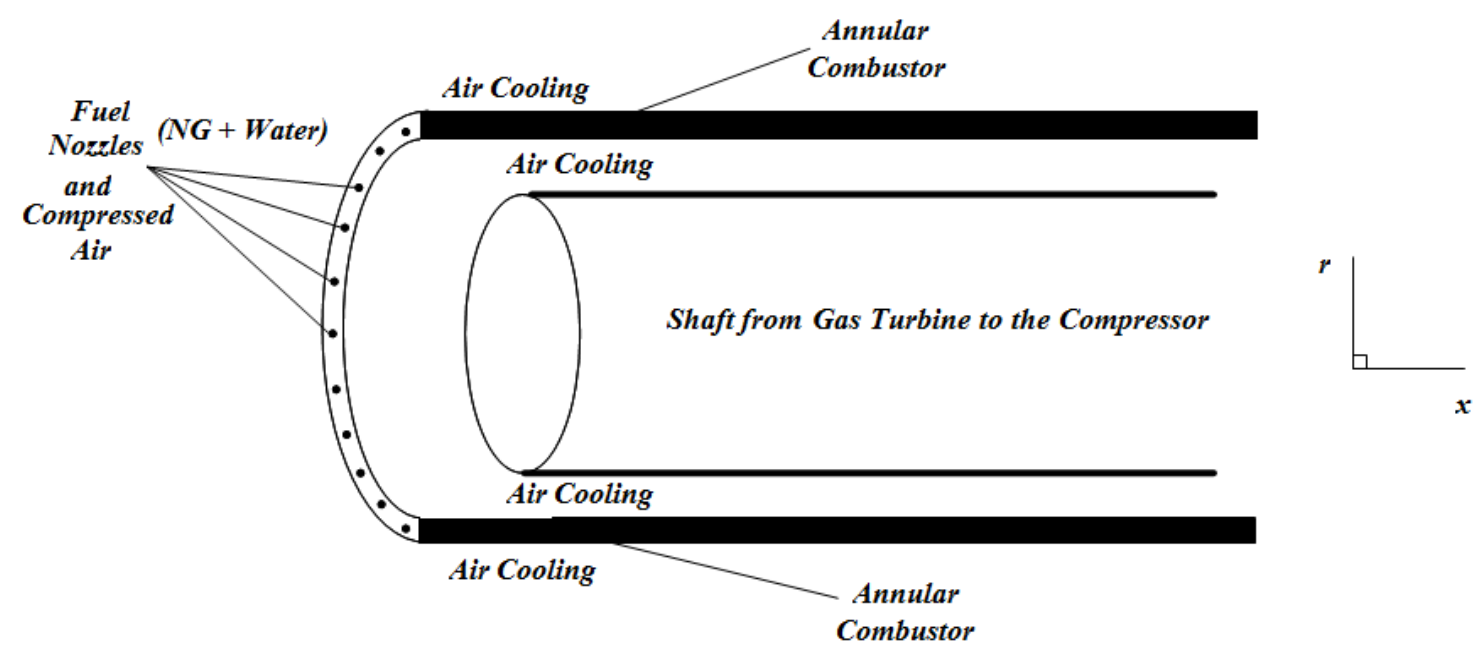

Figure 3: Cut-away view of the GE LM-2000 annular combustor

Figure 4 depicts a side view of the combustor along its length. The combustor can be modeled as three distinct zones: primary/flame, intermediate, and dilution. These compartmental models have been used previously to calculate the species concentrations and temperatures exiting turbine combustors [28, 30-35]. When using a chemical reactor network (CRN), the primary zone is usually modeled as multiple perfectly stirred reactors in parallel [30, 36-39], the intermediate zone as a single plug flow [37, 38] or perfectly stirred [30, 39] reactor, and the dilution zone generally as a plug flow reactor (PFR). The CRN used in this work is indicated in Figure $4 \mathrm{~b}$. The reaction kinetics in each zone, for natural gas combustion and $N O_{x}$ formation, consist of the well-known GRI-Mech 3.0 representation [26]. 

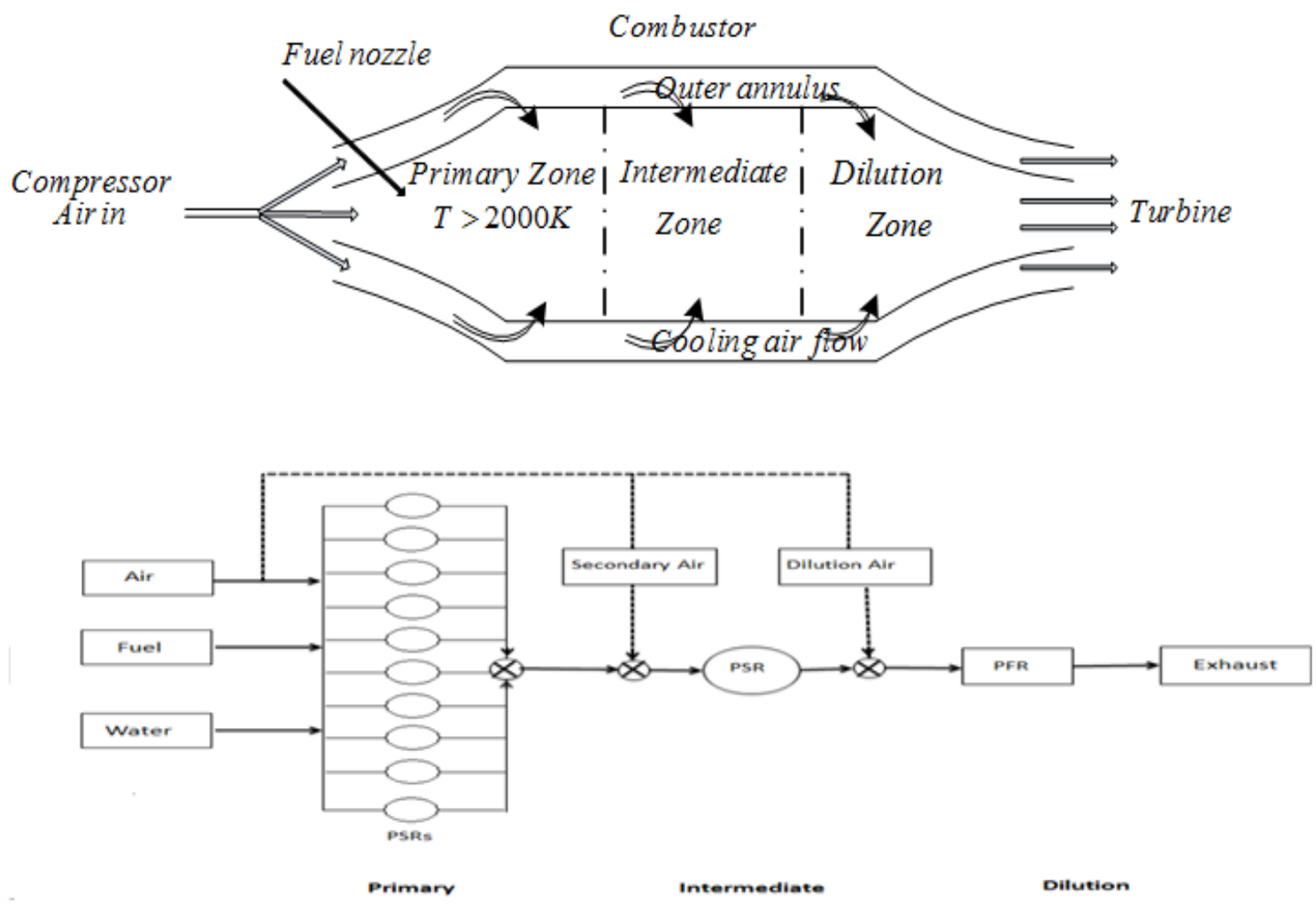

Figure 4: (a.) Schematic side view of combustor depicting the three reacting zones [40, 41], and (b.) our CRN model of the combustor.

\subsection{The Combustor Primary/Flame Zone}

In the primary combustion zone, air, fuel and water are injected into a highly-turbulent environment. Both fuel and water are delivered through each of the fuel nozzles. Of the $N O_{x}$ exiting the system is formed, $95+\%$ is formed here. With one perfectly stirred reactor (PSR) representing the primary zone, there can only be a single equivalence ratio $\varphi$ (fuel to air ratio normalized by the same ratio at stoichiometric conditions) for the zone. But when air and fuel mix, pockets of different equivalence ratios will be formed [42]. In a CRN we assume that the primary zone equivalence ratio can be approximated as a normal distribution about a mean [43]. For annular combustors, cold flow and CFD studies indicate an average equivalence ratio of 0.81 in the primary zone [42, 44]; however, average primary zone equivalence ratio values for all gas turbine combustors can range from 0.5 to 2.0 [45]. Experimental results for annular combustors $[37,46]$ also allow calculation of the primary zone equivalence ratio standard deviation when assuming a normal distribution. For a mean equivalence ratio in the primary zone of 0.81 the standard deviation of the equivalence ratio is found to be $0.38[37,46]$.

To represent the combustor using a CRN we follow the annular combustor modeling work of Allaire et al. [37] who used 16 PSRs in parallel to model the primary zone, followed by 3 PFRs in series to represent the intermediate and dilution zones. The use of 16 parallel PSRs was needed to account for measured $C O$ and $N O_{x}$ emissions when requiring $\Delta[C O]_{(i+1)}=$ 
$\left([\mathrm{CO}]_{(i+1)}-[\mathrm{CO}]_{(i)}\right) /[C \mathrm{CO}]_{(i)}<0.15$ and $\Delta\left[N O_{x}\right]_{(i+1)}<0.05$, where $i$ is the number of parallel PSRs. For our work, in order to similarly account for $\Delta[\mathrm{CO}]_{(i+1)}$ and $\Delta\left[\mathrm{NO}_{x}\right]_{(i+1)}$ we used 22 parallel PSRs in the primary zone. The total mass flow into the primary zone is divided equally among the 22 PSRs. In Figure 5, we show equivalence ratios (Figure 5a) and temperatures (Figure 5b) without water injection in these reactors.
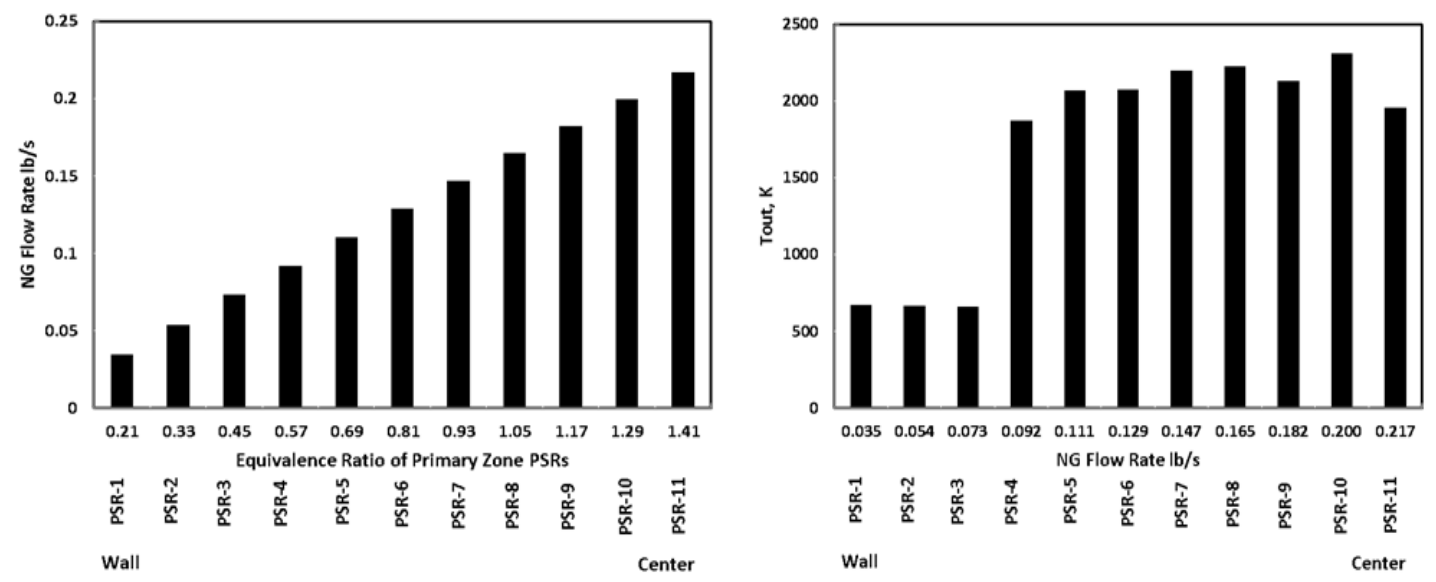

Figure 5: Fig 5 a.) Equivalence ratio versus natural gas flow rate in PSRs 1-11; Fig. 5b.) Natural gas flow rate versus temperature in PSRs 1-11 (radial symmetry). The equivalence ratio is $0.81 \pm 0.38$.

The different equivalence ratios result in different temperatures and $N O_{x}$ emission rates in the PSRs. For each PSR we used the same residence time (0.0015 s), but different volumes, given the different temperatures. This residence time is computed from the primary zone geometry, but with some minor adjustment to match up measured versus predicted $N O_{x}$ and $C O$. In Figure 5 a the average equivalence ratio is $0.81 \pm 0.38$.

In the primary zone, thermal $N O_{x}$, produced by oxidation of the nitrogen in air, is the dominant $N O_{x}$ mechanism $[47,48]$. We model the water injection as occurring in PSRs 6-17, those PSRs nearest to the centerline. Figure 6 shows that in PSRs 6-17 a water/fuel ratio of 1.34 is maintained, with a zero water/fuel ratio in PSRs 1-5 and 18-22. This water injection causes lower temperatures in PSRs 6-17, which affect the predicted $N O_{x}$ and $C O$ emissions. This assumed distribution gave a good match with experimental data and it was guided by our observation (discussed below) that damaged nozzles are often accompanied by abnormal water wear on the combustor walls. 


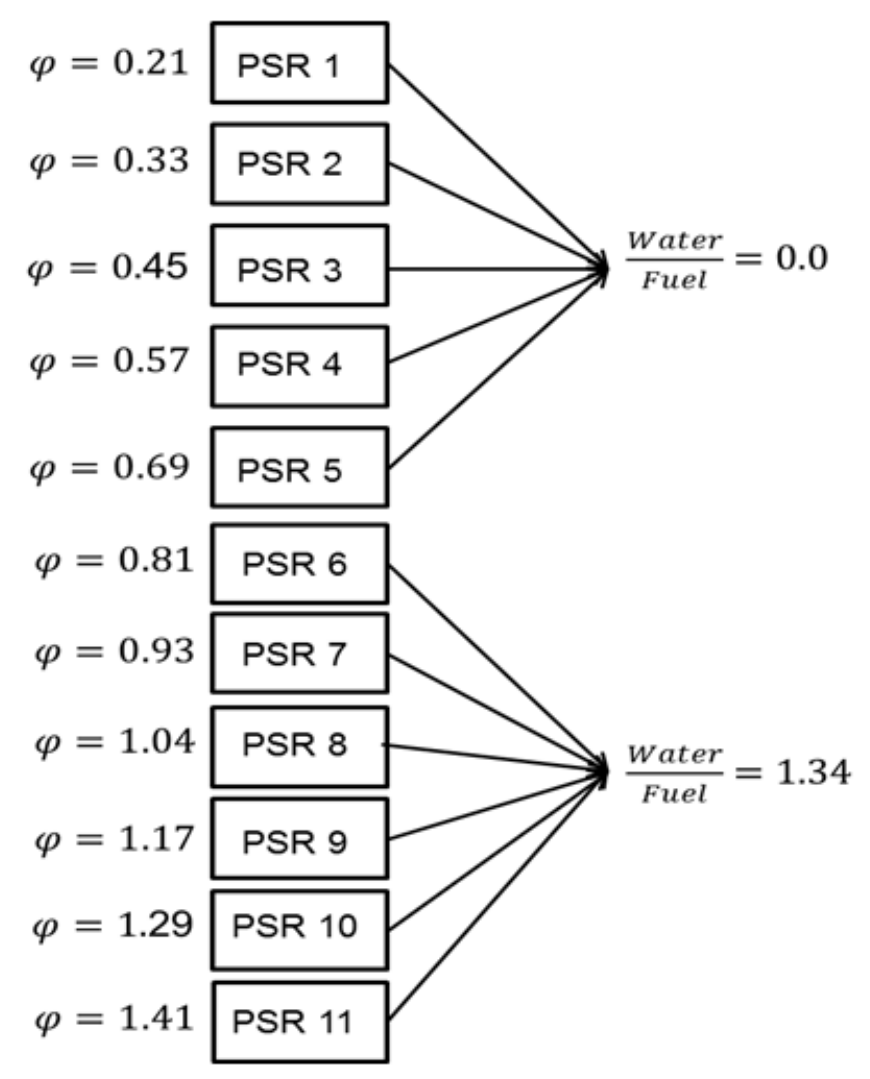

Figure 6: Distribution of water in the primary zone during normal operation (radial symmetry is assumed)

\subsection{Intermediate and Dilution Zones}

In the intermediate zone, exhaust products from the primary zone mix with additional air. The intermediate zone is modeled as a single PSR of residence time $0.035 \mathrm{~s}$, based solely on geometry. The temperature is high enough such that some oxidation of $\mathrm{CO}$ and $\mathrm{H}$ occurs, and a small amount of additional $N O_{x}$ formed. No further $N O_{x}$ is formed in the remainder of the system.

In the dilution zone, where additional air enters, the combustion products are cooled to avoid any degradation in the first stage of the turbine. The dilution zone is modeled as a single PFR of length $=6.3^{\prime \prime}$ (from geometric considerations). Overall then the entire combustor (primary, intermediate and dilution zones) is $~ 3.5^{\prime \prime}$ height $\mathrm{x} 75^{\prime \prime}$ width $\mathrm{x} 14^{\prime \prime}$ length.

At typical operating conditions (Table 1), the GE LM2000 uses $3.01 \mathrm{lb} / \mathrm{s}$ of natural gas fuel and $145 \mathrm{lb} / \mathrm{s}$ of air, a fuel/air ratio $=0.0208$. In the primary zone at design conditions the fuel requires $63.7 \mathrm{lb} / \mathrm{s}$ of air (equivalence ratio $=0.81$ ). The remaining air enters the intermediate and dilution zones and the turbine itself, to cool the blades. For calculation purposes we assumed $60 \%$ remaining air $(48.8 \mathrm{lb} / \mathrm{s})$ in the intermediate zone, $40 \%(32.5 \mathrm{lb} / \mathrm{s})$ in the dilution zone. If the combustor is operating properly, the $N O_{x}$ (lbs $N O_{x} / \mathrm{lb}$-total) and temperature leaving the primary zone will be the same for all total fuel/air ratios as long as the primary zone equivalence 
ratio is constant. The $N O_{x}$ concentration leaving the intermediate zone depends upon the air flow to that zone and on the reaction kinetics to a smaller extent.

\subsection{Solution Approach for the Annular Combustor}

Our solution approach was to combine the detailed chemical kinetics of GRI-Mech 3.0 (53 species and 325 elementary reactions) [26] with the material and energy balances for the PSRs and PFR [49]. This approach allowed prediction of $\mathrm{NO}_{x}, \mathrm{CO}$ and temperature from both zones. The energy balance and component material balances constitute a set of coupled ordinary differential equations [50], which were integrated using the CVODE (Lawrence Livermore National Laboratory) package [51]. Excel served as the pre- and post-processor [52] by calling CVODE as a dynamic link library.

$N O_{x}$ emissions depend upon the inlet air temperature to the combustor, the air and water flow rates, and the natural gas flow rate and composition. Figure 7 shows the $N O_{x}$ emissions predicted by the CRN (GRI-Mech 3.0 + PSRs + PFR models) as the fuel/air and water/fuel ratios change. The ratio ranges shown in Figure 7 were typical of operation of the cogeneration system, and they lead to measured and predicted $N O_{x}$ emissions ranging from 20 to 50 ppmvd.

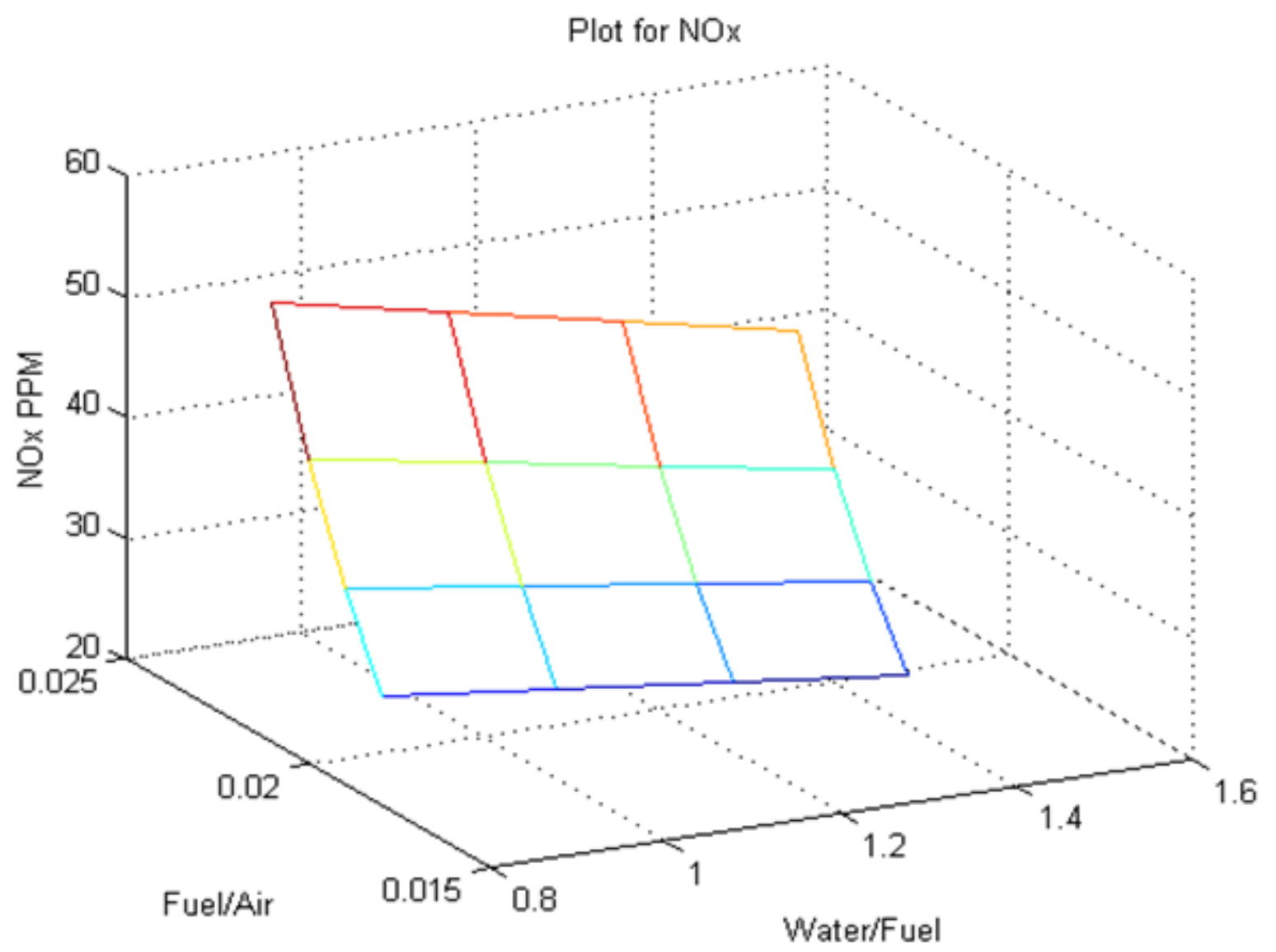

Figure $7 N O_{x}$ emissions (ppm) versus fuel/air and water/fuel ratios 
In Figure 8, the measured and predicted $N O_{x}$ and $C O$ emissions are compared as a function of the $\mathrm{C} / \mathrm{H}$ ratio in the natural gas when the system is at typical operating conditions. The CRN model consistently over predicts $N O_{x}$ emissions by $\sim 2.5$ ppmvd and under predicts the $C O$ emissions by $\sim 7-8$ ppmvd; similar $N O_{x}$ and $C O$ results have been found by others [38]. The small change in $N O_{x}$ emissions with fuel $\mathrm{C} / \mathrm{H}$ is expected [38].

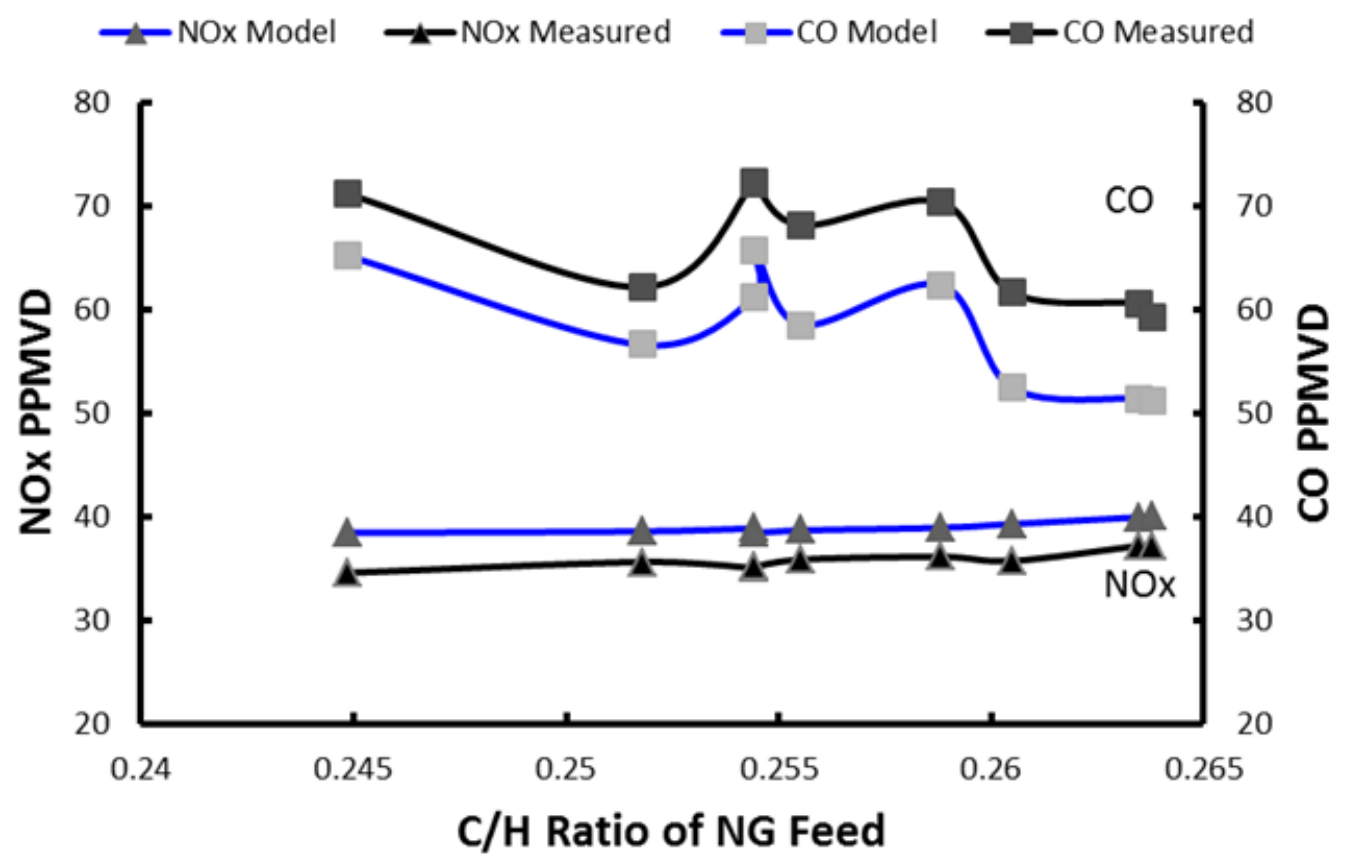

Figure 8 Measured versus predicted $N O_{x}$ and $C O$ as a function of natural gas $C / H$ at typical operating conditions of $F_{N G}=2.9-3.1 \mathrm{lbs} / \mathrm{s}, F_{\text {Air }}=140-150 \mathrm{lbs} / \mathrm{s}, F_{\text {Water }, \text { Inj }}=2.95-3.25 \mathrm{lbs} / \mathrm{s}$, with no fuel preheating.

The challenge then in developing an on-line diagnostic tool is coupling the predicted $N O_{x}$ concentrations with actual combustor operation over the entire range of operating conditions shown in Figure 7. It is CPU expensive to directly couple the data reconciliation with the CRN/kinetics emissions modeling. For a typical set of process measurements, data reconciliation by itself can take $10,000+$ iterations. A more tractable approach is to formulate narrow ranges for the measured variables that affect $N O_{x}$ emissions, and then curve fit the emissions calculated from the CRN over each range. This curve-fitted, reduced model can then be combined with the data reconciliation without a significant increase in solution time, the combination results in a fast $N O_{x}$ prediction model.

\section{Polynomial Approximations for NOx Emissions and Combustion Chamber Temperature}

In the primary zone, fuel and air are combusted with a fixed fuel/air ratio, while the remaining air is fed into the intermediate and dilution zones, with $\sim 10 \%$ of the total air used to cool the turbine blades. We assume for modeling and data reconciliation purposes that all air has been added by the end of the dilution zone and will be accounted for in the combustor energy balance. 
Doing so has no effect on predicted $N O_{x}$ or CO. We assign $\dot{Q}_{C C, L o s s}$ (combustion chamber heat loss) to the dilution zone, but any temperature change here also has no impact on the amount of $N O_{x}$ leaving the system, as verified kinetically.

If we assume $\dot{Q}_{C C \text {,Loss }}=0$ we can calculate the adiabatic temperature at the dilution zone exit, $T_{3}^{\text {adiabatic }}$, by two methods. A simple combustor energy balance allows $T_{3}^{\text {adiabatic }}$ to be determined. But we can also predict both $\mathrm{NO}_{x}$ and a unique $\mathrm{T}_{3}^{\text {adiabatic }}$ based on the primary and intermediate zone material and energy balances, along with the additional air flow rate to the dilution zone. The two values for $T_{3}^{\text {adiabatic }}$ will be virtually identical when using thermodynamically consistent kinetics databases and recognizing that the dominant reaction is just methane combustion to carbon dioxide and water.

Simulation results for $\mathrm{NO}_{x}$ emissions versus $\mathrm{T}_{3}^{\text {adiabatic }}$ for different water/fuel ratios and compressor discharge $T_{2}$ values (with $T_{\text {Fuel }}=520 \mathrm{R}$ ) are plotted in Figure 9. Along any curve in Figure 9, for example for $T_{2}=1206 \mathrm{R}$ and water/fuel $=0.8$, as the fuel to air ratio increases both $N O_{x}$ and $T_{3}^{\text {adiabatic }}$ will increase - both are uniquely determined, depending on fuel/air, water/fuel, $T_{2}$ and $T_{F u e l}$. But note that any selected $T_{3}^{\text {adiabatic }}$ can produce a range of $N O_{x}$ values, and any selected $N O_{x}$ value can produce a range of $T_{3}^{\text {adiabatic }}$ values. Therefore it is not possible to fit the data in Figure 9 to a single equation such as $T_{3}^{\text {adiabatic }}=f\left(N O_{x}\right)$.

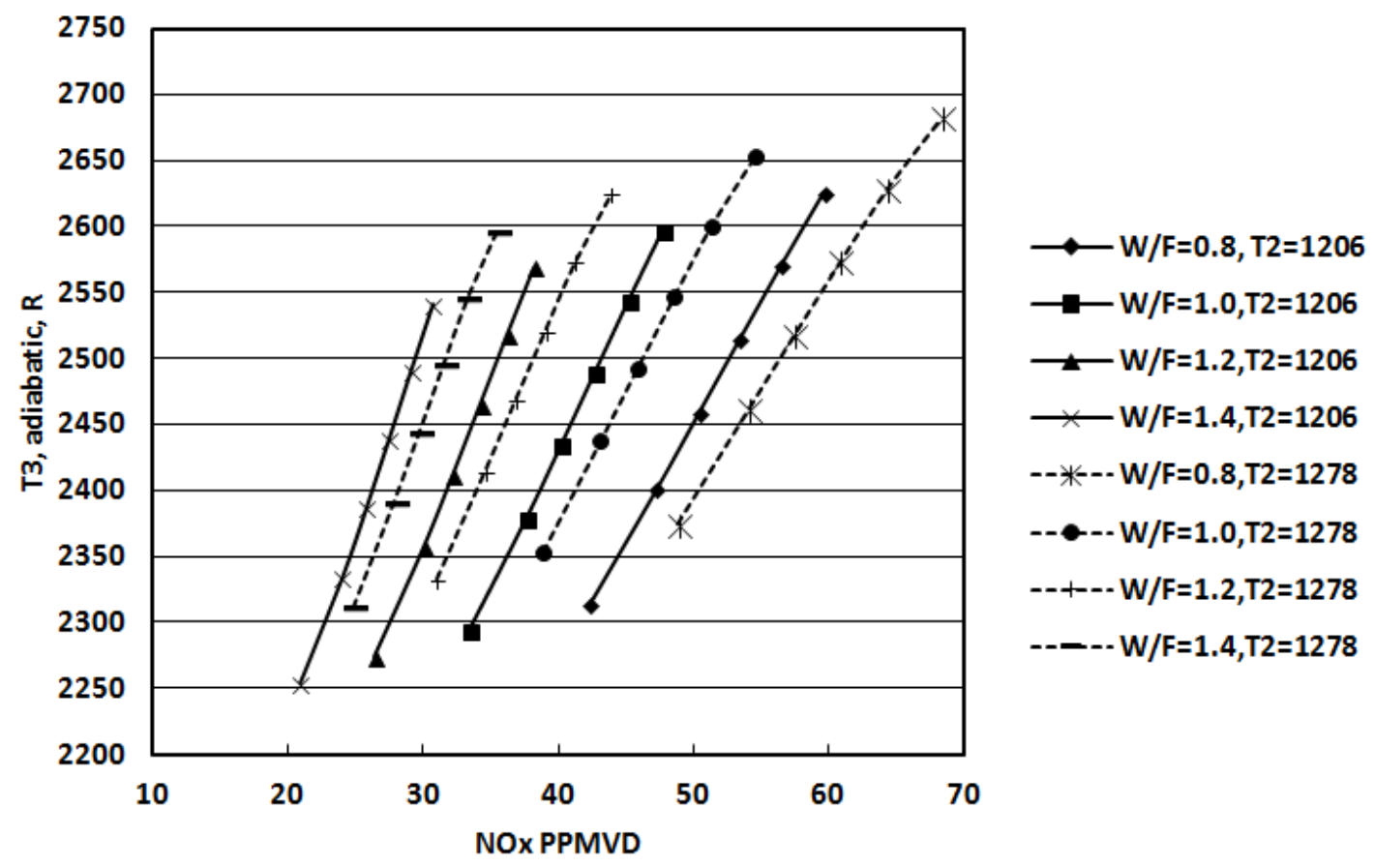

Figure $9 \mathrm{NO}_{x}$ versus $T_{3}^{\text {adiabatic }}$ as a function of water/fuel and $T_{2}$ values

However, it is possible to create a unique value for $T_{3}^{\text {adiabatic }}$ by multivariate curve fitting: 


$$
\begin{aligned}
& T_{3}^{\text {adiabatic }}=f\left[N O_{x}, \quad\left(\frac{\text { fuel }}{\text { air }}\right), \quad T_{2}, \quad\left(\frac{\text { water }}{\text { fuel }}\right), \text { and } T_{\text {Fuel }}\right]= \\
& T_{3}^{\text {adiabatic }}=A\left(N O_{x}\right)^{a}+B\left(\frac{\text { fuel }}{\text { air }}\right)^{b}+C\left(T_{2}\right)^{c}+D\left(\frac{\text { water }}{\text { fuel }}\right)^{d}+E\left(T_{\text {Fuel }}\right)^{e}
\end{aligned}
$$

For Equation (3) to also account for $T_{\text {Fuel }}$ and represent the data in Figures 7 and 9, some 15 separate equations (regions of parameter space) were required. These equations and accompanying regions are provided in Table A1 of the Appendix.

The curve fits here allow us to couple the measured $N O_{x}$ emissions (plus fuel, air and water flow rates and fuel and compressor discharge temperatures) to a unique $T_{3}^{\text {adiabatic }}$ and then a unique $T_{3}$ once $\dot{Q}_{C C, \text { Loss }}$ is accounted for. We can use the measured variables along with the measured $\mathrm{NO}_{x}$ emissions to predict $\mathrm{T}_{3}^{\text {adiabatic }}$ and $T_{3}$ (Eq. (3)). We can also determine $T_{3}^{\text {adiabatic } \text { and }}$ $T_{3}$ by energy balance on the combustor. Errors will arise in data reconciliation as conflicts develop between measured variables and the reconciled values needed to satisfy the energy and material balances around the compressor, combustion chamber, and both turbines, and Eq. (3). Gross error detection combined with suspect measurement identification completes the development of the improved on-line diagnostic tool.

In data reconciliation $T_{3}^{\text {adiabatic }}$ must be adjusted to $T_{3}$, the actual combustor exit temperature, by accounting for $\dot{Q}_{C C, \text { Loss }}$. To find the actual $T_{3}$ from $T_{3}^{\text {adiabatic }}$ we use:

$$
\hat{h}_{\text {Prod }, 3}=\hat{h}_{\text {Prod }, 3}^{\text {adiabatic }}-\frac{\dot{Q}_{C C, \text { Loss }}}{F_{\text {Prod }}}
$$

As the flow rates, $\mathrm{NO}_{x}$ concentration, $\mathrm{T}_{2}$ and $T_{\text {Fuel }}$ are varied during data reconciliation, $T_{3}^{\text {adiabatic }}$ is determined from the equations in Table A1 (Appendix), and $\hat{h}_{\text {Prod, } 3}^{\text {adiabatic }}$ is determined using the Peng-Robinson equation of state $[53,54] . \dot{Q}_{C C, \text { Loss }}$ and $F_{\text {Prod }}$ are also varied during data reconciliation, and for each iteration $\hat{h}_{P r o d, 3}$ was calculated.

\section{Results and Discussions - \\ Application of Improved On-line Diagnostic Tool for Cogeneration Systems}

\subsection{Enhanced On-Line Diagnostic Tool for Turbine Monitoring}

Before we provide examples utilizing the improved on-line diagnostic tool, we address the onset of combustor problems. As such problems develop, in particular due to poor distribution of fuel/water/air, emissions will increase, despite the fact that key measured variables may all remain within normal ranges (ranges reported in Figure 8).

As fuel nozzles become damaged due to blockage, cracks or abnormal wear, poor flow distribution of fuel and water can lead to increased $N O_{x}$ emissions and higher local temperatures in the primary zone [55]. These higher temperatures can result in metal fatigue and further 
erosion of the nozzles [56]. Figure 10 shows fuel/water injectors characterized by normal and abnormal wear; both nozzles were removed from the GE LM-2000 after 3 months ( 2000 h) operation.
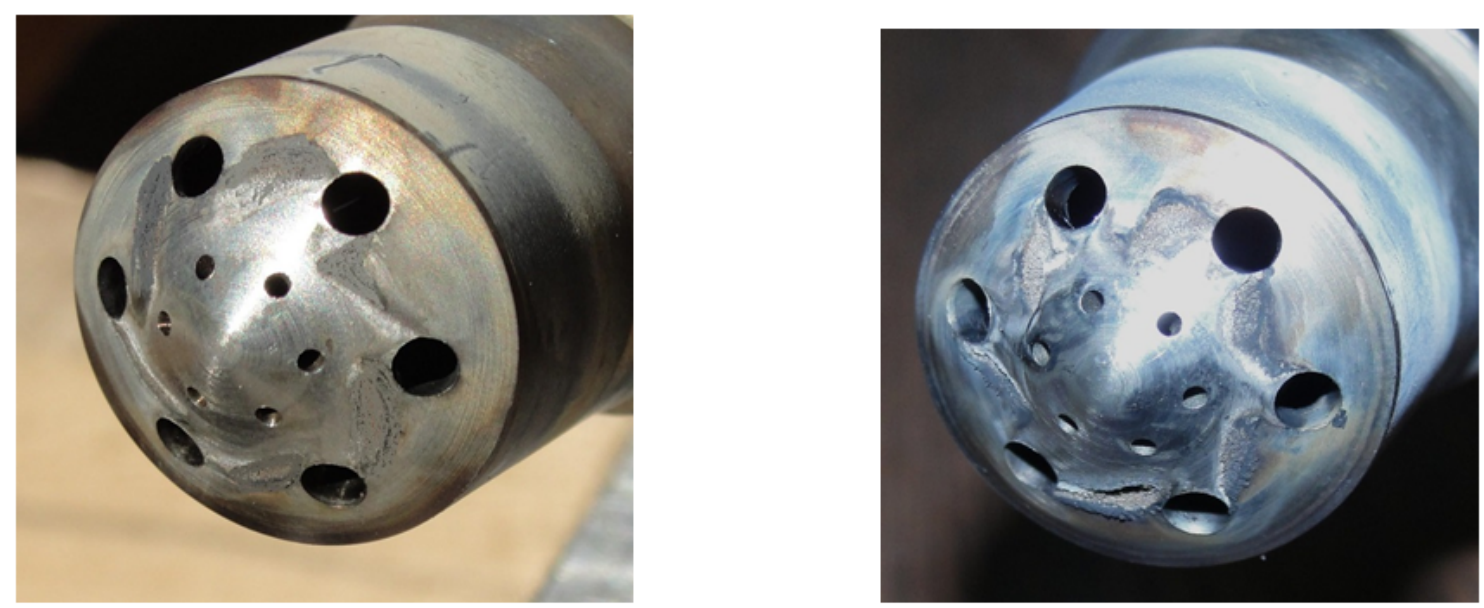

Figure 10 Fuel nozzles after $\sim 3$ months of operation. Fuel injection is through the 6 outer holes and water injection through the center 6 holes: a.) nozzle with normal wear; b.) nozzle with abnormal wear.

While figure 11 indicates that $T_{3}$ (determined from an overall energy balance around the combustor) might be the same regardless of nozzle conditions, a bad nozzle will result in a higher local $T_{\text {flame }}$, compared to a "design" nozzle, and the higher local $T_{\text {flame }}$ will cause an increase in $N O_{x}$.
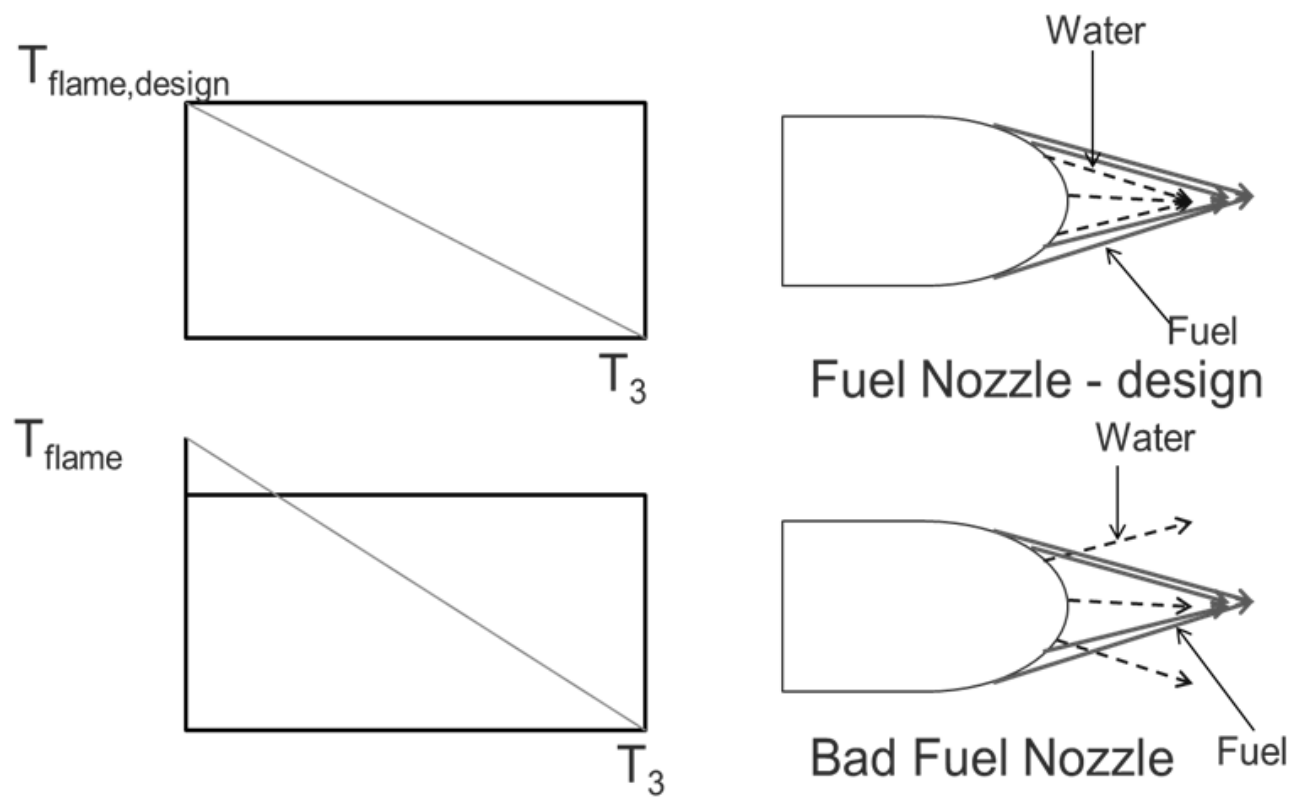
Figure $11 T_{\text {flame }}$ and the exit temperature from the combustor, $T_{3}$

\section{Example 1 - Using Emissions Monitoring for Suspect Measurement Identification}

In November measured $\mathrm{NO}_{x}$ emissions from the LSU cogeneration system gradually increased from 35 to 46 ppmvd (parts-per-million by dry volume) over three weeks. During this time period, no problems were detected by the standard cogeneration system diagnostics. The temperature difference between any two thermocouples at the power turbine inlet (Figure 2) remained less than $200 \mathrm{~F}$, and no excessive turbine vibration was detected.

For calculation purposes representative data, with the exception of the increased $N O_{x}$ emissions, can be found in Table 1. No fuel preheater was in use, so $T_{\text {Fuel }}=T_{0}$, and $T_{\text {Water, Inj }}=T_{0}$. Using the improved diagnostic tool, data reconciliation coupled with equation (3), we find the data reconciliation objective function (Eq. (1)) = 16.695.

The global test method [57] for gross error detection compares the least-squares objective function obtained in data reconciliation to a value of the chi-squared distribution, $\chi_{(1-\alpha)}^{2}(v)$, accounting for the desired error detection probability and the degree of redundancy (the number of material and energy balances around the cogeneration system):

$$
G T=\sum_{\substack{\text { i,measured } \\ \text { variables }}}\left(\frac{\left(x_{i}^{+}-x_{i}\right)}{\sigma_{i}}\right)^{2}<\chi_{(1-\alpha)}^{2}(v)
$$

In the distribution we used a 95\% detection probability, $\alpha=0.05$, and degree of redundancy $v=$ 8. In the 8 balances we have utilized $T_{3}$ calculated from Eqs. (3) and (4). Here $G T=16.695$ and $\chi_{(1-\alpha)}^{2}(v)=15.507$, so gross errors are detected $\left(G T>\chi_{(1-\alpha)}^{2}(v)\right)$.

The measurement test (MT) can pinpoint the most probable suspect measurement. The MT values were determined using Mah’s (1990) procedure.[19]

$$
M T_{i}=\frac{\left|a_{i}\right|}{\sqrt{V_{i i}}}
$$

where $a_{i}=\left(x_{i}^{+}-x_{i}\right)$ is an element of $a$, the adjustment vector, and $V_{i i}$ is on the diagonal of the covariance of $a$,

$$
V=\operatorname{cov}(a)=Q A^{T}\left(A Q A^{T}\right)^{-1} A Q
$$

$Q$ is the variance-covariance matrix (a diagonal matrix consisting of $\sigma_{i}^{2}$ ), and $A$ is the incidence matrix of the linearized constraints (the 6 linearized energy balances and 2 material balances). When a gross error is detected, the measurement test (Eq. (6)) points to the most likely suspects. 
However, it is recommended that non-redundant variables, i.e., those with adjustability $y_{i}<\sim$ 0.05, (a common industry standard) [58], or those below some other threshold value, be excluded from the gross error analysis. We calculate variable adjustability $_{i}=1-\frac{\sqrt{R_{i i}}}{\sigma_{i}}$, where $R_{i i}=Q_{i i}-V_{i i}$.

In order to use the $M T$ method to identify the likely suspect variables, we first need to linearize the energy balances. Linearizing the energy balances is straightforward for the air cooler, compressor/gas turbine, evaporator, and economizer. These balances only involve $F \hat{h}$ terms and here $\hat{h}=f(P, T)$. The remaining two balances include $\dot{Q}_{C C, L o s s}$ for the combustion chamber and $\dot{W}_{N e t}$ for the power turbine in addition to $F \hat{h}$ terms. The $\dot{Q}_{C C, \text { Loss }}$ and $\dot{W}_{\text {Net }}$ are considered known "leaks" and can be fixed at the data reconciliation solution. Therefore only the $F \hat{h}$ terms for the combustion chamber and power turbine balances must be linearized.

A subtle problem arises when linearizing the energy balance for the combustor. Generally this balance would contain $\left(F_{N G}\right)\left(\hat{h}_{N G}\right)$, but this can also be replaced by the lower heating value of the fuel $\left(F_{N G}\right)(L H V)$. Taking partial derivatives with respect to $F_{N G}$ gives either $L H V(\sim 21,500$ Btu/lb for natural gas) or $\hat{h}_{N G}(\sim-2000 \mathrm{Btu} / \mathrm{lb}$ when using the Peng-Robinson EOS with the enthalpy basis for each species its heat of formation at $77 \mathrm{~F}$ and 14.7 psia). This small value $\left(\hat{h}_{N G}\right)$ for the second partial derivative leads to an adjustability for $F_{N G}$ near 0 , which is unrealistic as $F_{N G}$ is the only system energy input. The combustor energy balance should be written:

$$
\begin{array}{r}
F_{N G}(L H V)+F_{\text {Air }}\left(\hat{h}_{\text {Air }, 2}-\hat{h}_{\text {Air,ref }}\right)+F_{\text {Water }, \text { Inj }}\left(\hat{h}_{\text {Water,Inj }}-\hat{h}_{\text {Water,Inj,ref }}\right) \\
=\left(F_{\text {Prod }} \hat{h}_{\text {Prod }, 3}-F_{\text {Prod }} \hat{h}_{\text {Prod,ref }}\right)+\dot{Q}_{C C, \text { Loss }}
\end{array}
$$

And the fuel LHV determined using an EOS as:

$$
L H V=\hat{h}_{N G}-\frac{F_{\text {Prod }} \hat{h}_{\text {Prod,ref }}-F_{\text {Air }} \hat{h}_{\text {Air, ref }}-F_{\text {Water,Inj }} \hat{h}_{\text {Water,Inj,ref }}}{F_{N G}}
$$

The suspect measurement order is found as, first, $F_{\text {Water,Inj }}$, with $M T_{F_{\text {Water,Inj }}}=19.57$, followed by the $N O_{x}$ concentration, with $M T_{N O_{x}}=3.04$, and then $T_{4}$, with $M T_{T_{4}}=3.00$. Recall that in Figure 8 the predicted $N O_{x}$ concentration was $8 \mathrm{ppm}$ above the experimental value of Table 1 , and therefore this concentration might be expected to show the largest $M T_{i}$. However, the most likely suspect measurement appears instead to be $F_{W a t e r, I n j}$.

It is common to exclude all virtually non-redundant variables (those with adjustability $_{i}<\sim$ $0.05)[22,58]$ from the measurement test analysis. According to this criterion $F_{\text {Blowdown }}, F_{C W}$, $T_{0}, T_{1}, T_{2}, F_{\text {Water,Inj }}$, and $T_{\text {Steam }}$ should be excluded from the measurement test analysis. The measurement test now results in $N O_{x}$ concentration as the most suspect, after accounting for variable adjustability. The $M T_{N O_{x}}$ came to 3.04, with $T_{4}$ as next most likely suspect measurement, with $M T_{T_{4}}=3.00$. 
These results indicate problems exist in the combustor, but with almost equal concerns about $N O_{x}$ and $T_{4}$ measurement at the exit of the gas generating turbine. However, there are actually 11 replicate measurements of $T_{4}$, enhancing the probability that the real source of problems is the combustor.

\subsection{Predicting the Onset of Malfunctioning Nozzles}

We have made the engineering simplification that the turbine annular combustor primary zone with 30 nozzles can be represented by a CRN consisting of 22 PSRs with known fuel/air distribution. Under normal operating conditions we assumed that the injected water was used by the PSRs representing the region near the combustor centerline, as indicated in Figures 6 and 12a. This assumed water distribution and the use of 22 PSRs in the primary zone gave the best agreement between experimental and predicted results for $N O_{x}$ and $\mathrm{CO}$ emissions, as shown in Figure 8. To simulate actual nozzles going bad, we assumed that some water flow would be redistributed from the PSRs near the centerline to the PSRs representing the region closer to the wall. This assumption was based on the observation that malfunctioning nozzles tend to also erode the combustor walls. In Figure 12 we consider the case where 3 fuel/water injection nozzles have gone bad and are maldistributing water. There are 30 actual nozzles, so $10 \%$ of the water flow rate would be redistributed from PSRs 6-17 to PSRs 1-5 and 18-22 as shown in Figure 12. We also assume that the fuel/air or equivalence ratio of each PSR is unaffected by water redistribution.
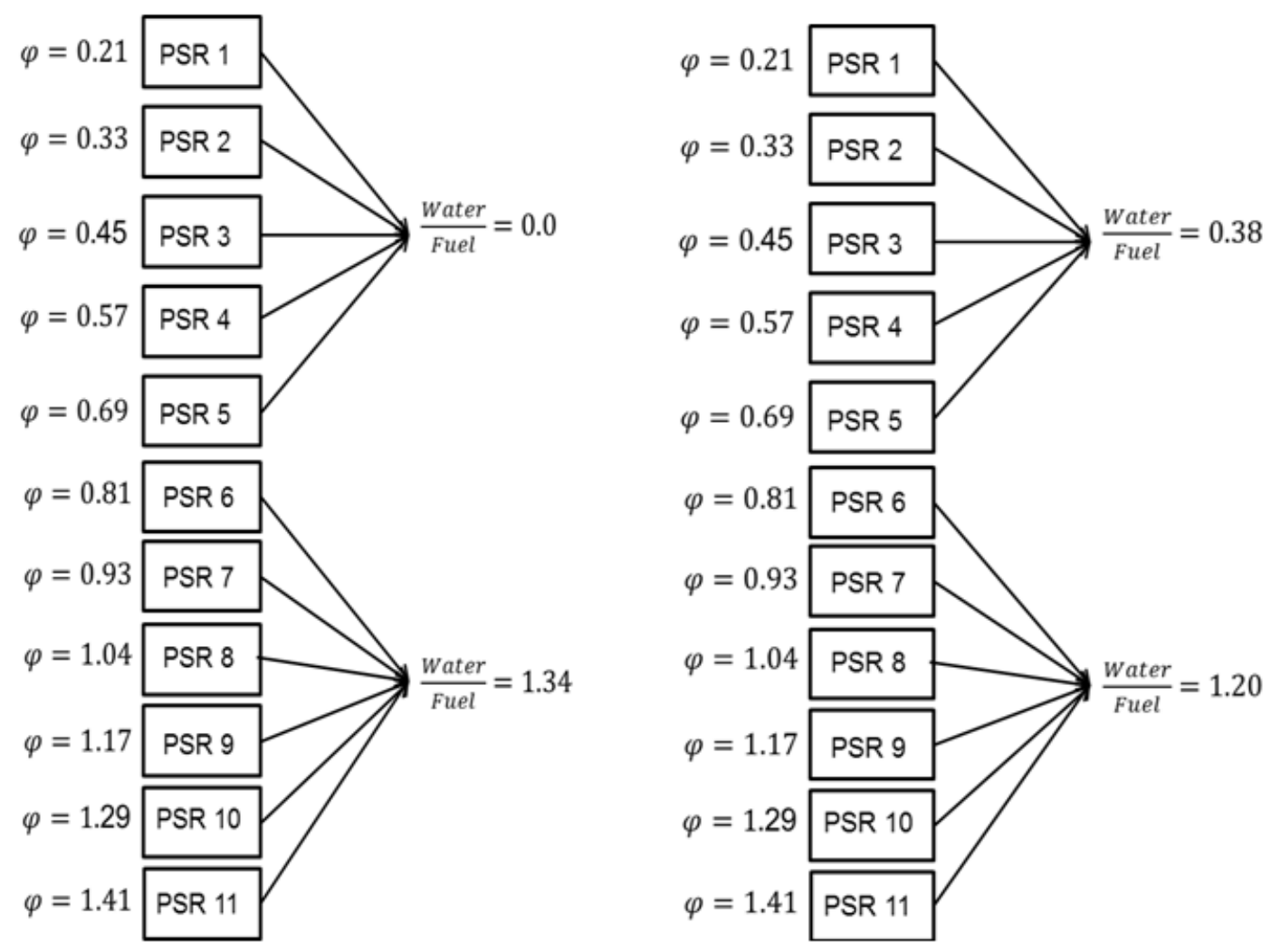
Figure 12: a.) Water injection in the primary zone during normal operation; b.) Water injection in the primary zone with 3 bad nozzles (radial symmetry assumed).

In Figure 13 we plot the calculated $N O_{x}$ emissions versus number of maldistributing (water) nozzles, assuming the same typical operating conditions as in Figure 8. The model predicts that for 3 maldistributing nozzles the $N O_{x}$ would increase from 38.5 to 42.3 ppmvd. For 10 bad nozzles the $N O_{x}$ emissions would increase $\sim 30 \%$, to $\sim 55$ ppmvd. Of course, there is no expectation that as all the nozzles fail or show excessive wear there will be an increase in water flow directed toward the wall. But it is reasonable to assume that malfunctioning nozzles will result in an increase in $N O_{x}$.

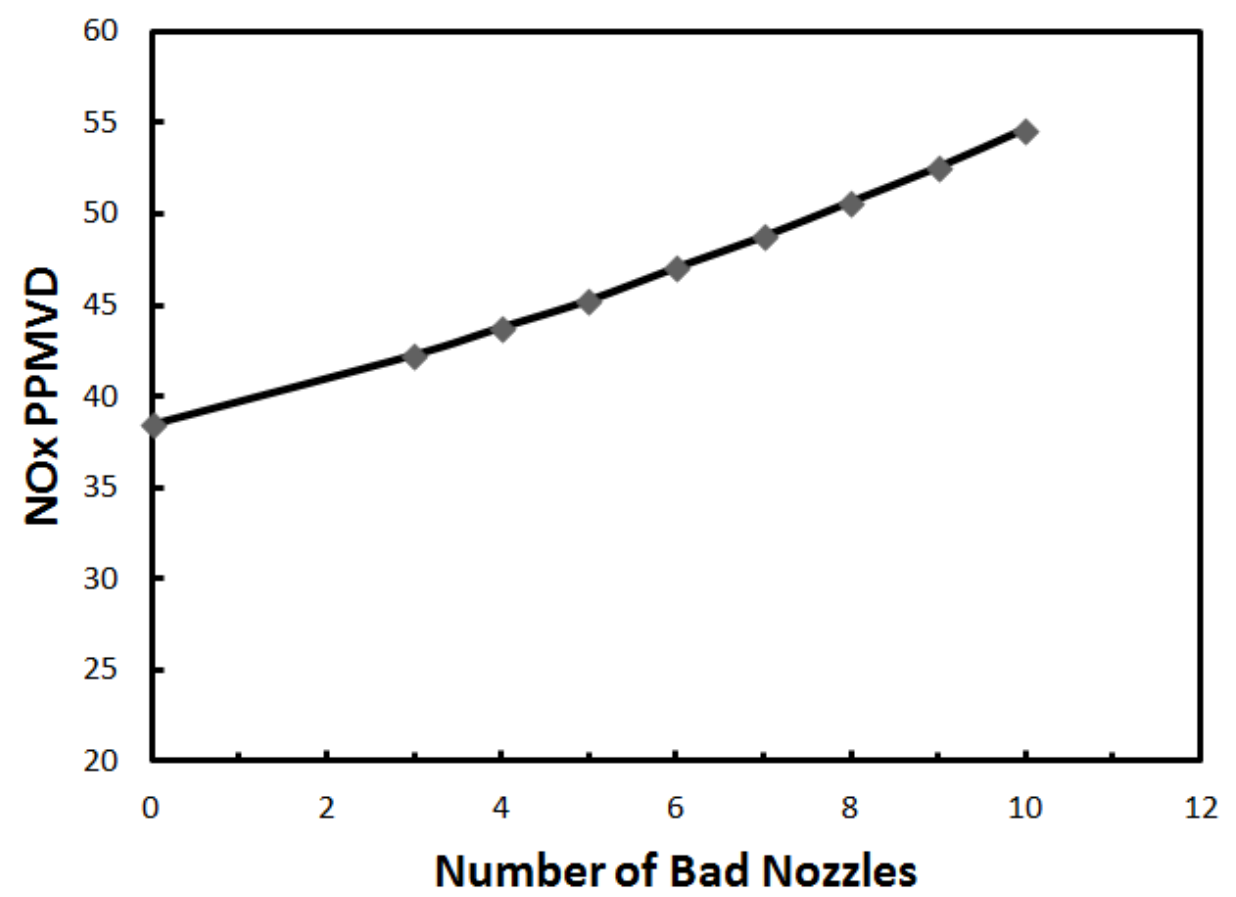

Figure 13: $N O_{x}$ emissions versus number of maldistributing nozzles. Operating conditions given in Figure 8.

\section{Example 2 - Predicting Malfunction Nozzles}

Here we use data from Example 1, where emissions increased from 35 to 46 ppmvd over a 3 week period, and Figure 13 to predict the number of nozzles that may be malfunctioning. In Example 1 the key reconciled values fall within typical operating values (as reported in Figure 8) and these values were used in Figure 13. Figure 13 suggests the observed emissions increase may be caused by 6-7 damaged nozzles in the combustor. The cogeneration facility was shut down in late November, and inspected. It was found that 8 fuel nozzles were damaged and needed to be replaced (two of the nozzles are shown in Figure 10). Here we attributed the increased $N O_{x}$ solely to the damaged injectors resulting in increased water flow towards the wall in the CRN. Other problems in the combustor, especially in the primary zone, can also result in increased $\mathrm{NO}_{x}$. 


\subsection{Sensitivity of the On-Line Diagnostic Tool for Turbine System Problem Identification}

While measured $N O_{x}$ emissions can be used within the data reconciliation process to help identify system problems, it is also important to appreciate the limitations of any data reconciliation process.

\section{Example 3 - Sensitivity of the Emissions Monitoring}

Consider the same problem as Example 1, data from Table 1, except $N O_{x}=42$ ppm (instead of $46 \mathrm{ppm})$. Data reconciliation indicates no gross errors, as $\chi_{(1-\alpha)}^{2}(v)=6.102\left(G T<\chi_{(1-\alpha)}^{2}(v)\right)$, but Figure 13 suggests 3 bad nozzles are present. This exemplifies the difficulties associated with gross error detection through data reconciliation. An error is often smeared into the errors of other measured variables during data reconciliation (see [29] for further discussion). Variable threshold calculations [20] provide further insight into these difficulties. We calculate that the $N O_{x}$ concentration would have to change by $12 \mathrm{ppm}$ to ensure gross error detection $90 \%$ of the time.

\section{Example 4 - Increase in Compressor Discharge Temperature}

Finally we caution that simply observing $N O_{x}$ values near 46 ppmvd as in Example 1 is not necessarily an indication of problems in the combustor. We performed data reconciliation with the measured variables of Table 1 and a measured $N O_{x}=46$ ppmvd, except we biased the exit air temperature from the compressor $\left(T_{2}\right)+36 \mathrm{R}$ from its value in Table 1 . Data reconciliation now results in $G T=7.427$, so, as $G T<\chi_{(1-\alpha)}^{2}(v)$, gross errors are not detected. Increases in $T_{2}$ can also result in increased $N O_{x}$ [59-63]. It is not possible to directly attribute an increase in $T_{2}$ to compressor fouling. However, as fouling also generally results in reductions in air flow, compressor discharge pressure and system net power, it is generally detectable.

\section{Conclusions}

Data reconciliation can be used to adjust measured data and help identify the onset of problems in a gas turbine-based cogeneration system. A CRN utilizing detailed kinetics modeling was combined with the measured $N O_{x}$ in order to enhance the data reconciliation process. Measured $N O_{x}$ emissions were related to the exit temperature of the combustor via a fast (curve fitted) $N O_{x}$ model, which segmented into 15 regions the combustor's operating parameters. The inclusion of the $N O_{x}$ emissions in data reconciliation allowed the detection of a wider range of system problems, especially within the combustor itself. To the author's knowledge this is the first reported use of $N O_{x}$ emissions to enhance the data reconciliation process. Standard diagnostic tools including vibration monitoring, turbine temperature distribution and data reconciliation, 
without utilizing measured $N O_{x}$, do not always show degradation in injector or combustor performance. However, the use of data reconciliation requires experience to pinpoint specific problem locations, and care in addressing well-known data reconciliation issues such as variable adjustability and error smearing.

\section{Acknowledgements}

We acknowledge the financial assistance of the National Science Foundation, Phase II grant, "Energy Sustainability Remote Laboratory (ESRL)," NSF award (1323202). We thank Dr. Michael Erbes (Enginomix, LLC) and Peter Davidson (LSU) for their insights into gas turbine operations. We also acknowledge OSIsoft (in particular Sherwood Pilgrim) for providing their PI software (Version 3.4.375.38) used for data collection and archiving.

Appendix. Constants used in Equation (3) to determine adiabatic temperature in the combustor

Table A1: $T_{3}^{\text {adiabatic }}=A\left(N O_{x}\right)^{a}+B\left(\frac{\text { fuel }}{\text { air }}\right)^{b}+C\left(T_{2}\right)^{c}+D\left(\frac{\text { water }}{\text { fuel }}\right)^{d}+E\left(T_{\text {Fuel }}\right)^{e}$ for GE LM-2000

\begin{tabular}{|c|c|c|c|c|c|c|c|c|c|c|c|}
\hline$\frac{\text { water }}{\text { fuel }}$ & $\frac{\text { fuel }}{\text { air }}$ & A & $a$ & B & $b$ & C & C & $D$ & $d$ & E & $e$ \\
\hline \multirow{5}{*}{$0.8-1.0$} & $\begin{array}{c}0.0165- \\
0.0180 \\
\end{array}$ & 1237.537 & 0.206 & 113.056 & 0.92 & 39.884 & 0.0011 & -308.534 & -1.324 & 0.558 & 0.01 \\
\hline & $\begin{array}{c}0.0180- \\
0.0190\end{array}$ & 1289.061 & 0.192 & 104.665 & 1.2 & 53.218 & 0.0091 & -266.311 & -1.363 & 0.0358 & 0.01 \\
\hline & $\begin{array}{c}0.0190- \\
0.0200\end{array}$ & 1224.984 & 0.198 & 104.33 & 2.22 & 51.447 & 0.0091 & -158.729 & -2.08 & 0.459 & 0.01 \\
\hline & $\begin{array}{c}0.0200- \\
0.0210\end{array}$ & 1255.641 & 0.1935 & 106.22 & 1.22 & 51.347 & 0.0091 & -156.926 & $\begin{array}{l}-2.06 \\
\end{array}$ & 0.459 & 0.01 \\
\hline & $\begin{array}{c}0.0210- \\
0.0220\end{array}$ & 1425.074 & 0.173 & 109.74 & 1.19 & 52.817 & 0.0099 & $\begin{array}{l}-266.058 \\
\end{array}$ & -1.22 & 0.5425 & 0.0048 \\
\hline \multirow{5}{*}{$1.0-1.2$} & $\begin{array}{c}0.0165- \\
0.0180\end{array}$ & 1198.776 & 0.213 & 110.445 & 1.232 & 39.884 & 0.0011 & -308.534 & -1.324 & 0.558 & 0.01 \\
\hline & $\begin{array}{c}0.0180- \\
0.0190\end{array}$ & 1327.824 & 0.19 & 95.422 & 1.09 & 54.109 & 0.0091 & -325.379 & -1.742 & 0.0358 & 0.01 \\
\hline & $\begin{array}{c}0.0190- \\
0.0200\end{array}$ & 1277.161 & 0.196 & 106.73 & 1.255 & 52.379 & 0.0099 & -250.136 & -2.388 & 0.332 & 0.0099 \\
\hline & $\begin{array}{c}0.0200- \\
0.0210\end{array}$ & 1296.965 & 0.1923 & 107.791 & 1.198 & 56.122 & 0.0099 & -237.655 & -2.48 & 0.2426 & 0.007 \\
\hline & $\begin{array}{c}0.0210- \\
0.0220\end{array}$ & 1447.911 & 0.1741 & 109.996 & 1.124 & 56.123 & 0.011 & -325.993 & $\begin{array}{l}-1.53 \\
\end{array}$ & 0.6227 & 0.023 \\
\hline \multirow{5}{*}{$1.2-1.4$} & $\begin{array}{c}0.0165- \\
0.0180\end{array}$ & 1269.109 & 0.1984 & 102.33 & 1.2 & 53.522 & 0.0091 & -398.086 & -3.359 & 0.0358 & 0.01 \\
\hline & $\begin{array}{c}0.0180- \\
0.0190\end{array}$ & 1397.13 & 0.1835 & 101.254 & 2.229 & 54.098 & 0.01 & $\begin{array}{l}-441.96 \\
\end{array}$ & -1.994 & 0.0358 & 0.01 \\
\hline & $\begin{array}{c}0.0190- \\
0.0200\end{array}$ & 1311.186 & 0.1924 & 107.234 & 2.22 & 53.596 & 0.091 & -372.82 & -3.405 & 0.4586 & 0.01 \\
\hline & $\begin{array}{c}0.0200- \\
0.0210\end{array}$ & 1364.139 & 0.188 & 109.708 & 1.191 & 53.239 & 0.0099 & -387.463 & -2.713 & 0.5425 & 0.0048 \\
\hline & $\begin{array}{c}0.0210- \\
0.0220\end{array}$ & 1538.626 & 0.167 & 102.48 & 1.338 & 57.477 & 0.011 & -456.829 & $\begin{array}{l}-1.53 \\
\end{array}$ & 0.2767 & 0.022 \\
\hline
\end{tabular}




\section{$\underline{\text { References }}$}

[1] Loboda I. Gas Turbine Diagnostics. In: Konstantin V, editor. Efficency, Performance and Robustness of Gas Turbines 2012.

[2] Finn J, Wagner J, Bassily H. Monitoring strategies for a combined cycle electric power generator. Applied Energy. 2010;87:2621-7.

[3] Li YG, Nilkitsaranont P. Gas turbine performance prognostic for condition-based maintenance. Applied Energy. 2009;86:2152-61.

[4] Li YG. Gas Turbine Performance and Health Status Estimation Using Adaptive Gas Path Analysis. Journal of Engineering for Gas Turbines and Power. 2010;132:041701-9.

[5] Ogaji SOT, Marinai L, Sampath S, Singh R, Prober SD. Gas-turbine fault diagnostics: a fuzzy-logic approach. Applied Energy. 2005;82:81-9.

[6] Mohammadi E, Montazeri-Gh M. A fuzzy-based gas turbine fault detection and identification system for full and part-load performance deterioration. Aerospace Science and Technology. 2015;46:82-93.

[7] Li YG, Ghafir MFA, Wang L, Singh R, Huang K, Feng X. Nonlinear Multiple Points Gas Turbine Off-Design Performance Adaptation Using a Genetic Algorithm. Journal of Engineering for Gas Turbines and Power. 2011;133:071701-.

[8] Romessis C, Mathioudakis K. Bayesian Network Approach for Gas Path Fault Diagnosis. Journal of Engineering for Gas Turbines and Power. 2004;128:64-72.

[9] Zaidan MA, Mills AR, Harrison RF, Fleming PJ. Gas turbine engine prognostics using Bayesian hierarchical models: A variational approach. Mechanical Systems and Signal Processing. 2016;70-71:120-40.

[10] Zaidan MA, Relan R, Mills AR, Harrison RF. Prognostics of gas turbine engine: An integrated approach. Expert Systems with Applications. 2015;42:8472-83.

[11] Lazzaretto A, Toffolo A. Analytical and neural network models for gas turbine design and off-design simulation. International Journal of Thermodynamics. 2010;4:173-82.

[12] Vanini ZNS, Meskin N, Khorasani K. Multiple-Model Sensor and Components Fault Diagnosis in Gas Turbine Engines Using Autoassociative Neural Networks. Journal of Engineering for Gas Turbines and Power-Transactions of the Asme. 2014;136.

[13] Tayarani-Bathaie SS, Khorasani K. Fault detection and isolation of gas turbine engines using a bank of neural networks. Journal of Process Control. 2015;36:22-41.

[14] Loboda I, Robles MAO. Gas Turbine Fault Diagnosis Using Probabilistic Neural Networks. International Journal of Turbo \& Jet-Engines. 2015;32:175-91.

[15] Volponi AJ, DePold H, Ganguli R, Daguang C. The Use of Kalman Filter and Neural Network Methodologies in Gas Turbine Performance Diagnostics: A Comparative Study. Journal of Engineering for Gas Turbines and Power. 2003;125:917-24.

[16] Doel DL. An Assessment of Weighted-Least-Squares-Based Gas Path Analysis. Journal of Engineering for Gas Turbines and Power. 1994;116:366-73.

[17] Doel DL. Interpretation of Weighted-Least-Squares Gas Path Analysis Results. Journal of Engineering for Gas Turbines and Power. 2003;125:624-33.

[18] Li YG, Korakianitis T. Nonlinear Weighted-Least-Squares Estimation Approach for GasTurbine Diagnostic Applications. Journal of Propulsion and Power. 2011;27:337-45.

[19] Mah RSH. Chemical Process Structure and Information Flows. Stoneham, MA: Butterworths; 1990. 
[20] Madron F. Process Plant Performance - Measurement and Data Processing for Optimization and Retrofits. New York NY: Ellis Horwood; 1992.

[21] Madron F, Hostalek M, Stepan L. Protection of a Nuclear Reactor Monitoring System against Gross Measurement Errors. International Journal of Nuclear Energy Science and Engineering. 2015;5:9-18.

[22] Jiang X, Liu P, Li Z. A data reconciliation based framework for integrated sensor and equipment performance monitoring in power plants. Applied Energy. 2014;134:270-82.

[23] Martini A, Sorce A, Traverso A, Massardo A. Data Reconciliation for power systems monitoring: Application to a microturbine-based test rig. Applied Energy. 2013;111:1152-61.

[24] Lee AJ, Diwekar UM. Optimal sensor placement in integrated gasification combined cycle power systems. Applied Energy. 2012;99:255-64.

[25] Luo X, Hu J, Zhao J, Zhang B, Chen Y, Mo S. Multi-objective optimization for the design and synthesis of utility systems with emission abatement technology concerns. Applied Energy. 2014;136:1110-31.

[26] Smith GP, Golden DM, Frenklach M, Moriarty NW, Eiteneer B, Goldenberg M, et al. GRIMech 3.0. http://www.me.berkeley.edu/gri_mech/; 1999.

[27] Law CK, Sung CJ, Wang H, Lu TF. Development of Comprehensive Detailed and Reduced Reaction Mechanisms for Combustion Modeling. AIAA Journal. 2003;41:1629-46.

[28] Knopf FC. Modeling Analysis and Optimization of Process and Energy Systems. Hoboken, NJ: John Wiley \& Sons Inc.; 2012.

[29] Syed MS, Dooley KM, Carl Knopf F, Erbes MR, Madron F. Data Reconciliation and Suspect Measurement Identification for Gas Turbine Cogeneration Systems. Journal of Engineering for Gas Turbines and Power. 2013;135:091701-.

[30] Andreini A, Facchini B. Gas Turbines Design and Off-Design Performance Analysis With Emissions Evaluation. Journal of Engineering for Gas Turbines and Power. 2004;126:83-91.

[31] Cuoci A, Frassoldati A, Stagni A, Faravelli T, Ranzi E, Buzzi-Ferraris G. Numerical Modeling of NOx Formation in Turbulent Flames Using a Kinetic Post-processing Technique. Energy \& Fuels. 2012;27:1104-22.

[32] Fichet V, Kanniche M, Plion P, Gicquel O. A reactor network model for predicting NOx emissions in gas turbines. Fuel. 2010;89:2202-10.

[33] Kanniche M. Coupling CFD with chemical reactor network for advanced NOx prediction in gas turbine. Clean Technologies and Environmental Policy. 2010;12:661-70.

[34] Rizk NK, Mongia HC. Semianalytical Correlations for $\mathrm{NO}_{\mathrm{x}}, \mathrm{CO}$, and UHC Emissions. Journal of Engineering for Gas Turbines and Power. 1993;115:612-9.

[35] Rizk NK, Mongia HC. A Semi-Analytical Emission Model for Diffusion Flame, Rich/Lean and Premixed Lean Combustors. Journal of Engineering for Gas Turbines and Power. 1995;117:290-301.

[36] Broadwell JE, Lutz AE. A Turbulent Jet Chemical Reaction Model: NOx Production in Jet Flames. Combustion and Flame. 1998;114:319-35.

[37] Allaire DL, Waitz IA, Willcox KE. A Comparison of Two Methods for Predicting Emissions From Aircraft Gas Turbine Combustors. Proceedings of the ASME Turbo Expo 20072007. p. 899-908.

[38] Mendoza Orbegoso EM, Romeiro CD, Ferreira SB, Figueira Da Silva LF. Emissions and Thermodynamic Performance Simulation of an Industrial Gas Turbine. Journal of Propulsion and Power. 2011;27:78-93. 
[39] Celis C, Moss B, Pilidis P. Emissions Modelling for the Optimization of Greener Aircraft Operations. in ASME Turbo Expo 2009: Power for Land, Sea, and Air. 2009;2:167-78.

[40] Swithenbank J, Poll I, Vincent MW, Wright DD. Combustion design fundamentals. Fourteenth Symposium (International) on Combustion, The Combustion Institute. Pittsburgh, PA 1972. p. 627-38.

[41] Yamamoto T, Furuhata T, Arai N, Gupta AK. Prediction of NOx Emissions from Hightemperature Gas Turbines: Numerical Simulation for Low-Nox Combustion. JSME International Journal. 2002;45:19.

[42] Heywood JB, Mikus T. Parameters controlling nitric oxide emissions from gas turbine combustors. AGARD Atmospheric Pollution by Aircraft Engines. 1973: 05-20.

[43] Rizk NK, Chin JS, Marshall AW, Razdan MK. Predictions of NOx Formation Under Combined Droplet and Partially Premixed Reaction of Diffusion Flame Combustors. Journal of Engineering for Gas Turbines and Power. 2002;124:31-8.

[44] Tuccillo R, Cameretti MC. Combustion and Combustors for MGT Applications. VKI/RTO Lecture Series on" Micro Gas Turbines2005. p. 5-1 - 5-56.

[45] Meher-Homji CB, Zachary J, Bromley AF. Gas Turbine Fuels-System Design, Combustion, and Operability. Proceedings of the 39th Turbomachinery Symposium Texas A\&M University2010. p. 155-86.

[46] Sturgess GJ, Zelina J, Shouse DT, Roquemore WM. Emissions Reduction Technologies for Military Gas Turbine Engines. Journal of Propulsion and Power. 2005;21:193-217.

[47] Lefebvre AH. The Role of Fuel Preparation in Low-Emission Combustion. Journal of Engineering for Gas Turbines and Power. 1995;117:617-54.

[48] Smoot LD, Hill SC, Xu H. NOx control through reburning. Progress in Energy and Combustion Science. 1998;24:385-408.

[49] Syed MS. A New Diagnostics Tool for Water Injected Gas Turbines - Emissions Monitoring and Modeling [Ph.D.]: Louisiana State University; 2013.

[50] Syed MS, Punuru JR, Dooley KM, Knopf FC. A Readily Accessible Platform for Detailed Combustion Emissions Calculations. International Journal of Mechanical Engineering Education. 2012;40:289-304.

[51] Cohen SD, Hindmarsh AC. CVODE, a stiff/nonstiff ODE solver in C. Comput Phys. 1996;10:138-43.

[52] Punuru JR, Knopf FC. Bridging Excel and $\mathrm{C} / \mathrm{C}++$ code. Computer Applications in Engineering Education. 2008;16:289-304.

[53] Kandula VK, Telotte JC, Knopf FC. Its Not as Easy as it Looks: Revisiting Peng-Robinson Equation of State Convergence Issues for Dew, Bubble and Flash Calculations. International Journal of Mechanical Engineering Education. 2013;41:188-202.

[54] Peng D-Y, Robinson DB. A New Two-Constant Equation of State. Industrial \& Engineering Chemistry Fundamentals. 1976;15:59-64.

[55] Boyce MP. The Gas Turbine Engineering Handbook. 3rd ed. Burlington, MA: Gulf Professional Publishing; 2006.

[56] Phillips JN, Simas P. Gas Turbine Fuel Nozzle Refurbishment: Follow these Guidelines to improve Reliability and Reduce Emissions Hydrocarbon Processing. Pocasset, MA2004. p. 1-3.

[57] Romagnoli JA, Sánchez MC. Data Processing and Reconciliation for Chemical Process Operations. San Diego, CA: Academic Press; 2000. 
[58] Madron F, Veverka V, Hostalek M. Process Data Validation in Practice: Applications from Chemical, Oil, Mineral and Power Industries. Report CPT-229-07, ChemPlant Technology. http://www.chemplant.cz/dwnld.htm (last accessed January, 2013)2007.

[59] Meher-Homji CB. Gas Turbine Axial Compressor Fouling: A Unified Treatment of its Effects, Detection, and Control. International Journal of Turbo and Jet Engines. 1992;9:311-34.

[60] Meher-Homji CB, Chaker M, Bromley AF. The Fouling of Axial Flow Compressors: Causes, Effects, Susceptibility, and Sensitivity. Proceedings of the Eighteenth Turbomachinery Symposium: ASME; 2009.

[61] Diakunchak I. Performance deterioration in industrial gas turbines. Journal of Engineering for Gas Turbines and Power;(United States). 1992;114:161-8.

[62] Meher-Homji CB, Bromley A. Gas turbine axial compressor fouling and washing. Proceedings of the 33rd Turbomachinery Symposium. 2004:20-3.

[63] Singh R, Murthy J. A Computational Study of Some of The Implications For Gas Turbine Design and Maintenance as a Consequence of NO. 18th CIMAC Conference, Tiajin, China1989. 